\title{
Alpha-pinene isomerization on acid-treated clays
}

\author{
Nurgün Beşün ${ }^{\mathrm{a}, *}$, Fehime Özkan ${ }^{\mathrm{b}}$, Gönül Gündüz ${ }^{\mathrm{a}}$ \\ ${ }^{a}$ Ege University, Faculty of Engineering, Chemical Engineering Department, 35100 Bornova, İzmir, Turkey \\ ${ }^{\mathrm{b}}$ Izmir Institute of Technology, Faculty of Engineering, Chemical Engineering Department, 35230 Çankaya, İzmir, Turkey
}

Received 24 April 2001; received in revised form 29 August 2001; accepted 29 August 2001

\begin{abstract}
Liquid phase isomerization of $\alpha$-pinene was studied over a number of differently pre-treated montmorillonite clays. The effects of the acid pre-treatment parameters (acid-to-clay ratio (A/C), water-to-acid ratio (W/A), temperature and pre-treatment time) on the product distribution were investigated. It was observed that the pre-treatment with acid improved the catalytic activity of that catalyst which was activated at $200{ }^{\circ} \mathrm{C}$ for $4 \mathrm{~h}$ at $\mathrm{A} / \mathrm{C}$ ratios between 0.2 and 0.4 .

Alpha-pinene consumption was very small over the catalysts prepared with an $\mathrm{A} / \mathrm{C}$ ratio of 0.8 . Characterization studies that were done by nitrogen and water vapor adsorption experiments and by IR measurements showed that catalysts with high differential pore volumes for pores around $2 \mathrm{~nm}$ and homogenous mesopore distributions and with low dealumination degrees were good catalysts for the production of camphene. Catalysts having heterogeneous mesoporosity were found to be the preferable ones for limonene production. () 2002 Elsevier Science B.V. All rights reserved.
\end{abstract}

Keywords: Alpha-pinene; Isomerization; Camphene; Acid-activated clay

\section{Introduction}

Isomerization of $\alpha$-pinene over $\mathrm{TiO}_{2}$ [1-6] is a conventional way to produce camphene which is an important intermediate in camphor synthesis. The latter is used in the fragrance and pharmaceutical industries. Both organic and inorganic catalysts have been reported in the literature to promote direct isomerization of $\alpha$-pinene to camphene. The preparation methods have a great influence both on the yield and on the composition of product mixture. The catalysts based on titanium dioxide [1-6], clay [7-9], halloysite [10,11], natural [10-14] or synthetic [15] zeolite and carbon [16], are treated usually with an acid to activate their surfaces. This activation improves the

\footnotetext{
* Corresponding author. Tel.: +90-232-388-4000x2292; fax: +90-232-3887600.

E-mail address: besunnur@superonline.com (N. Beșün).
}

behavior of the catalysts so that yields of camphene as high as $50 \%$ are reached [1-9].

The acid catalyzed isomerization of $\alpha$-pinene proceeds via two parallel pathways: one leads to bi- and tricyclic products, such as camphene, $\beta$-pinene, tricyclene and bornylene by ring expansion, while the other produces monocyclic products such as dipentene (limonene), terpinolene, $p$-cymene and $\alpha$ - or $\gamma$ terpinenes [6] (Fig. 1). The acidity of the catalyst has a remarkable influence on the ratio of the bi- and tricyclic molecules to monocyclic products.

Acid-activated clays have attracted considerable attention as catalysts for a variety of acid-mediated reactions. Isomerization of $\alpha$-pinene is one of these reactions. Many one-step methods with clay based catalysts have been suggested for the preparation of camphene and tricyclene with different samples of Albanian clay activated by $10 \% \mathrm{HCl}$. Albanian clays were divided into four groups according to the rate of 


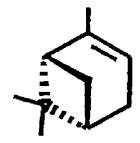

I

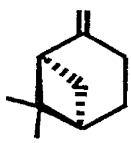

VI

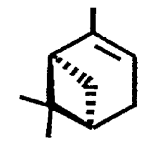

II

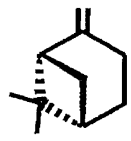

VII

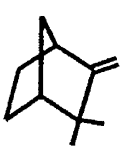

III

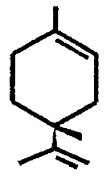

VIII

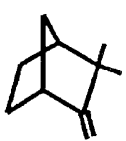

IV

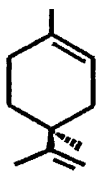

IX

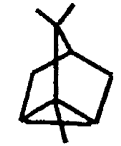

V

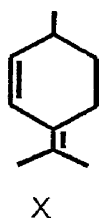

Fig. 1. Structural formulas of terpene compounds: I: $\alpha$-pinene; II: camphene; III: tricyclene; IV: limonene; V: terpinolene; VI: $\gamma$-terpinene; VII: $\alpha$-terpinene; VIII: $p$-cymene; IX: $\beta$-phellanderene; and X: $\alpha$-phellanderene.

the isomerization of $\alpha$-pinene into camphene. It was found that, when the isomerization of $\alpha$-pinene was complete, the isomerization products contained 30\% camphene and $10 \%$ tricyclene independently on what type of activated clay was used as catalyst. Kullaj [8] investigated the relationship between same characteristics, such as, $\mathrm{pH}$ or specific surface area of clays activated with $10 \% \mathrm{HCl}$ and the rate of the isomerization of $\alpha$-pinene into camphene and tricyclene but it was not possible to relate them. However, it was observed that the highest rate of isomerization of $\alpha$-pinene to camphene was obtained when the $\mathrm{SiO}_{2} / \mathrm{Al}_{2} \mathrm{O}_{3}$ mole ratio was equal to 5 or 6 . Nazir et al. [9] used China and fire clays as catalysts for the isomerization of $\alpha$-pinene to camphene. The best yields were obtained with $2 \%$ China clay treated with $\mathrm{H}_{2} \mathrm{SO}_{4}$ and activated at $350{ }^{\circ} \mathrm{C}$.

In another work of Allahverdiev et al. [17], the kinetics of the liquid-phase isomerization of $\alpha$-pinene over a natural zeolite-clinoptilolite was studied at $100-180^{\circ} \mathrm{C}$ and nitrogen pressures $1-20$ bar. Up to $80-85$ wt. \% of conversion selectivity toward reaction products was constant with camphene and limonene as the main products. Only at relatively high conversion were other monocylic and tricylic products formed. The consumption rate of $\alpha$-pinene followed first-order kinetics. Temperature dependence of the first-order kinetic constant obeyed Arrhenius dependence with the activation energy equal to $80.9 \mathrm{~kJ} / \mathrm{mol}$. Selectivities at particular conversions were seen to be independent of temperature and pressure. A reaction network and mechanism were advanced and the corresponding kinetic equations were derived. The kinetic model gave a good correlation between the theoretical and experimental data.

Yamamoto et al. [18] studied the generation of acid sites on silica-supported rare earth oxide catalysts in order to determine the active site for $\alpha$-pinene isomerization. Silica-supported rare earth oxides exhibit solid acidity for catalysts of $\alpha$-pinene isomerization, and the activities strongly depend on the supported element. In the lanthanoid series ( $\mathrm{La}, \mathrm{Pr}, \mathrm{Sm}, \mathrm{Eu}, \mathrm{Tb}$, and $\mathrm{Yb}$ ), the activity increased continuously with atomic number from $\mathrm{La}$ to $\mathrm{Yb}$. $\mathrm{Ce} / \mathrm{SiO}_{2}$ was inert for this reaction, and crystalline $\mathrm{CeO}_{2}$ was formed. $\mathrm{Y} / \mathrm{SiO}_{2}$ exhibited the same activity as $\mathrm{Yb} / \mathrm{SiO}_{2}$. All the $\mathrm{Ln} / \mathrm{SiO}_{2}$ catalysts, except for $\mathrm{Ce} / \mathrm{SiO}_{2}$, are amorphous and form $\mathrm{Ln}-\mathrm{O}-\mathrm{Si}$ and/or Ln-O-Ln linkages with different compositions in each catalyst. The affinity among the $\mathrm{LnO}_{n}$ units and $\mathrm{SiO}_{4}$ tetrahedra depends on the size of $\mathrm{Ln}^{3+}$. With increasing ratio of $\mathrm{Ln}-\mathrm{O}-\mathrm{Si}$ to $\mathrm{Ln}-\mathrm{O}-\mathrm{Ln}$ linkages, the catalytic activity increases.

Excess loading of $\mathrm{Yb}$ atoms to $\mathrm{SiO}_{2}$, blocks the $\mathrm{Yb}-\mathrm{O}-\mathrm{Si}$ linkages of the active site to form $\mathrm{Yb}_{2} \mathrm{O}_{3}$ fine particles. When $\mathrm{Yb} / \mathrm{SiO}_{2}$ was pre-treated at $1273 \mathrm{~K}$, fine ytterbium silicate did not exhibit catalysis. The Ln-O-Si linkage in $\mathrm{Ln} / \mathrm{SiO}_{2}$ having no long-ranged ordering structure is the active site for $\alpha$-pinene isomerization.

Some authors have also studied acid-base properties of silica-supported ytterbium oxide catalyst, loading amounts of which were $25 \mu \mathrm{mol}-8.4 \mathrm{mmol}$ $\mathrm{Ybg}\left(\mathrm{SiO}_{2}\right)^{-1}$ in $\alpha$-pinene isomerization [19]. 
In one research, the $\alpha$-pinene isomerization reaction was studied on sulfated zirconium oxide catalyst for different experimental conditions. The catalysts were active for producing camphene when they presented Brönsted acidity and when zirconium oxide crystallized in the tetragonal phase. The $\alpha$-pinene conversion of operating conditions, such as, temperature, catalyst concentration and reaction time. The use of this catalyst in the appropriate conditions could result in selectivity to camphene to about $70 \%$ [20].

Severino et al. [16], studied the liquid phase isomerization of $\alpha$-pinene on a number of zeolite catalysts at $150^{\circ} \mathrm{C}$. The primary reaction products were camphene, tricyclene and $p$-menthadienes. Catalyst samples with lattice $\mathrm{Si} / \mathrm{Al}$ ratios ranging from 1.46 to ca. 200 were prepared by hydrothermal treatment of zeolites $\mathrm{Y}$ and $\mathrm{X}$. The nature of extra-framework aluminum species was investigated by Al-MAS-NMR spectroscopy. For high values of $N_{\mathrm{Al}}$ (number of framework aluminum atoms per unit cell), extra-aluminum (EFAL) species had a promoting effect on the catalytic activity. On the other hand, for the highly dealuminated samples the catalytic activity decreased with $N_{\mathrm{Al}}$. However, it did not seem to become zero for zero Brönsted acidity, suggesting that Lewis acid sites were also active on $\alpha$-pinene isomerization. Selectivity towards camphene was also strongly affected by EFAL species, decreasing at high values of $N_{\mathrm{Al}}$, and increasing for the catalyst samples with high EFAL content. The different distribution of EFAL species in the catalysts prepared at different temperatures would cause this effect on selectivity. Severino et al. state that as Lewis acid sites are weaker than Brönsted sites, camphene and bicyclic products are preferentially formed on the Lewis sites, while, monocylic products are preferentially formed on the framework Brönsted sites.

The acid pre-treatment removes octahedral ions such as $\mathrm{Al}, \mathrm{Fe}, \mathrm{Mg}$, and isomorphously substituted tetrahedral ions from the montmorillonite clay. The extent of the removal of these ions depends on the pre-treatment temperature, the strength of the acid, the acid-to-clay ratio $(\mathrm{A} / \mathrm{C})$, the water-to-acid ratio (W/A) and the duration of the pre-treatment [21].

The objective of this work is to study the effects of acid pre-treatment activation parameters on some physical properties (such as surface area, pore size distribution and structural changes) of montmoril- lonite clays and to relate them to the isomerization of $\alpha$-pinene, especially to the conversion of $\alpha$-pinene and to the selectivities towards camphene and limonene.

\section{Experimental study}

\subsection{Catalyst preparation}

The catalyst used in the experiments was activated clay. Clay (montmorillonite) obtained from the firm of MADAK, Balikesir, Turkey was activated by the dry method [22]. First raw clay was dried at $105^{\circ} \mathrm{C}$ and was reduced to size of $40 \mu \mathrm{m}$ in diameter. Then, clay sample was mixed with acid (98\% technical $\mathrm{H}_{2} \mathrm{SO}_{4}$ ) and distilled water to form a thick slurry keeping the $\mathrm{A} / \mathrm{C}$ and W/A ratios at different known values (A/C ratio: 0.2 or 0.4 or 0.8 ; W/A ratio: 1.2 or 4 ). Activated clay samples were washed with distilled water and the $\mathrm{pH}$ was adjusted at 3-3.5. Eventually, the catalyst obtained was re-dried in an oven at $105^{\circ} \mathrm{C}$ for $4 \mathrm{~h}$ and reduced to size of $0.05 \mathrm{~mm}$ in diameter.

\subsection{Apparatus and reaction}

The catalysts prepared were tested in the isomerization reaction of $\alpha$-pinene. Reaction was carried out at atmospheric pressure under nitrogen flow in a glass reactor with a reflux condenser, an efficient stirrer and a temperature controller. Five hundred milligrams of catalyst and $50 \mathrm{~g}$ of wood turpentine (Ortas, Edremit, Turkey) containing $85 \mathrm{wt} . \% \alpha$-pinene were charged in the reactor. All experiments were carried out under isothermal $\left(155^{\circ} \mathrm{C}\right)$ conditions. Samples of the reaction mixture were taken during the course of the reaction and analyzed by flame ionization detector (FID) gas chromatography (Hewlett-Packard 5980/2 with $25 \mathrm{~m}$ and $0.32 \mathrm{~mm}$ i.d. HP-FFAP capillary column) connected to a mass spectrometer with electron energy $70 \mathrm{eV}$ and mass rate $35-425 \mathrm{~m} / \mathrm{z}$. Temperature programming (increase at a rate of $2{ }^{\circ} \mathrm{C} / \mathrm{min}$ from 60 to $130^{\circ} \mathrm{C}$ and onwards at a rate $3{ }^{\circ} \mathrm{C} / \mathrm{min}$ until $215^{\circ} \mathrm{C}$ ) was applied for separation at $1 \mathrm{ml} / \mathrm{min}_{2}$ flow.

\subsection{Catalyst characterization}

Nitrogen adsorption experiments were performed at $77 \mathrm{~K}$ using a static volumetric apparatus (Coulter Om- 
nisorp 100cx) up to $P / P_{0} \sim 0.95$. The samples were previously degassed at pre-treatment temperatures of clays for $4 \mathrm{~h}$. Specific total surface areas and monolayer pore volumes were calculated using Langmuir equation and specific pore volumes were estimated from the nitrogen uptake. On the other hand, water adsorption isotherms to $P / P_{0} \sim 0.90$ at $25^{\circ} \mathrm{C}$ were determined in the same volumetric apparatus.

It is well known that [23] water is adsorbed in monomolecular layers between the silicate laminae like other many polar but otherwise neutral molecules. This water is accommodated reversibly regardless of heat treatment below ca. $300^{\circ} \mathrm{C}$; above $500^{\circ} \mathrm{C}$ water can be removed and the laminae are bound together irreversibly. After calcination at $600^{\circ} \mathrm{C}$, that is, after the conversion of the clay to a silica/alumina catalyst, no water is adsorbed in the interlaminar areas. According to Mooney, Keenan and Wood, the interlaminar area is the difference in water and nitrogen surface areas. By means of the chemical analysis of clay and the interlaminar area obtained, a crystal model can be developed for montmorillonite lattice [23]. But this is out of the scope of the present study.

IR spectra of the activated clays were recorded on $\mathrm{KBr}$ wafers $(1.2 \mathrm{mg}$ catalyst and $150 \mathrm{mg} \mathrm{KBr})$ to determine dealumination degrees with a Shimadzu 470 instrument. On the other hand, IR spectroscopic studies of pyridine adsorbed on solid surfaces make it possible to distinguish between Brönsted and Lewis acid and to assess their amounts independently [24]. The spectrum of pyridine coordinately bonded to surface is very different from that of the pyridinium ion. As stated in the literature peaks observed at 1450, 1490 and $1545 \mathrm{~cm}^{-1}$ correspond to Lewis acid sites, Lewis and Brönsted acid sites, and Brönsted acid sites, respectively. IR spectra of the pyridine adsorbed catalysts were recorded on $\mathrm{KBr}$ wafers $(8 \mathrm{mg}$ catalyst and $100 \mathrm{mg} \mathrm{KBr}$ ) with Shimadzu 470 instrument. IR analysis take place at room temperature and atmospheric pressure.

Catalytic activity studies were carried out in a glass, isothermal reactor. The reaction mixture was stirred vigorously to eliminate the external diffusion resistance between the bulk liquid and the catalyst surface. Results of internal diffusion studies showed that, in the particle size used, the influence of internal mass transfer resistance was also negligible.

\section{Results and discussion}

\subsection{Adsorption studies}

Typical nitrogen adsorption isotherms are reproduced in Fig. 2 and typical water adsorption isotherms in Fig. 3. The shape of the nitrogen adsorption isotherms is quite different from the water vapor adsorption isotherms. The asymptotic approach to limiting quantity is observed in nitrogen isotherms, whereas, limited adsorption is not observed in water vapor adsorption. As shown in Fig. 2, the nitrogen adsorption isotherms of clay catalysts prepared are similar to type 2 in the classification of Brunauer, Deming, Deming and Teller (BDDT). Differentially, there was no plateau indicating the completion of mesopore filling at high relative pressures $\left(P / P_{0}\right)$.

During the water vapor adsorption on the clay the particles may be split into smaller platy particles, but the interlameller adsorption was accomplished by swelling and development of an accessible internal area. So these isotherms show great volumes adsorbed in the interlaminar spaces. That is why, the adsorption capacity of the clay with respect to nitrogen is increased at all relative pressures. Water isotherms are quite similar to each other except the isotherms for $\mathrm{A} / \mathrm{C}$ ratio of 0.8 , which is the maximum $\mathrm{A} / \mathrm{C}$ ratio studied, that is, acid amount is the highest in the acid treatment process for these clays (Fig. 3). The break in the adsorption isotherm observed at relative pressures between 0.40 and 0.43 is not uncommon among montmorillonites [23]. This indicates the expansion of layer lattice of clay with the interlayer formation of water.

Table 1 gives the nitrogen and water vapor surface areas of the acid-treated clay catalysts. To arrive a more realistic quantitative amount of the external surface area of clay the $t$-method was employed [25]. The micropore surface areas were calculated by subtracting the external area from the BET surface area. It is clear that the water vapor surface areas are much greater than the nitrogen surface areas, as expected. In general, the acid treatment causes a decrease in the micropore area, whereas, an increase in external area compared to those of raw clay. The comparison of the micropore surface areas of the clay catalysts treated at $\mathrm{A} / \mathrm{C}=0.4$ and $\mathrm{W} / \mathrm{A}=4$ shows that these surface areas decrease with increasing pre-treatment temper- 

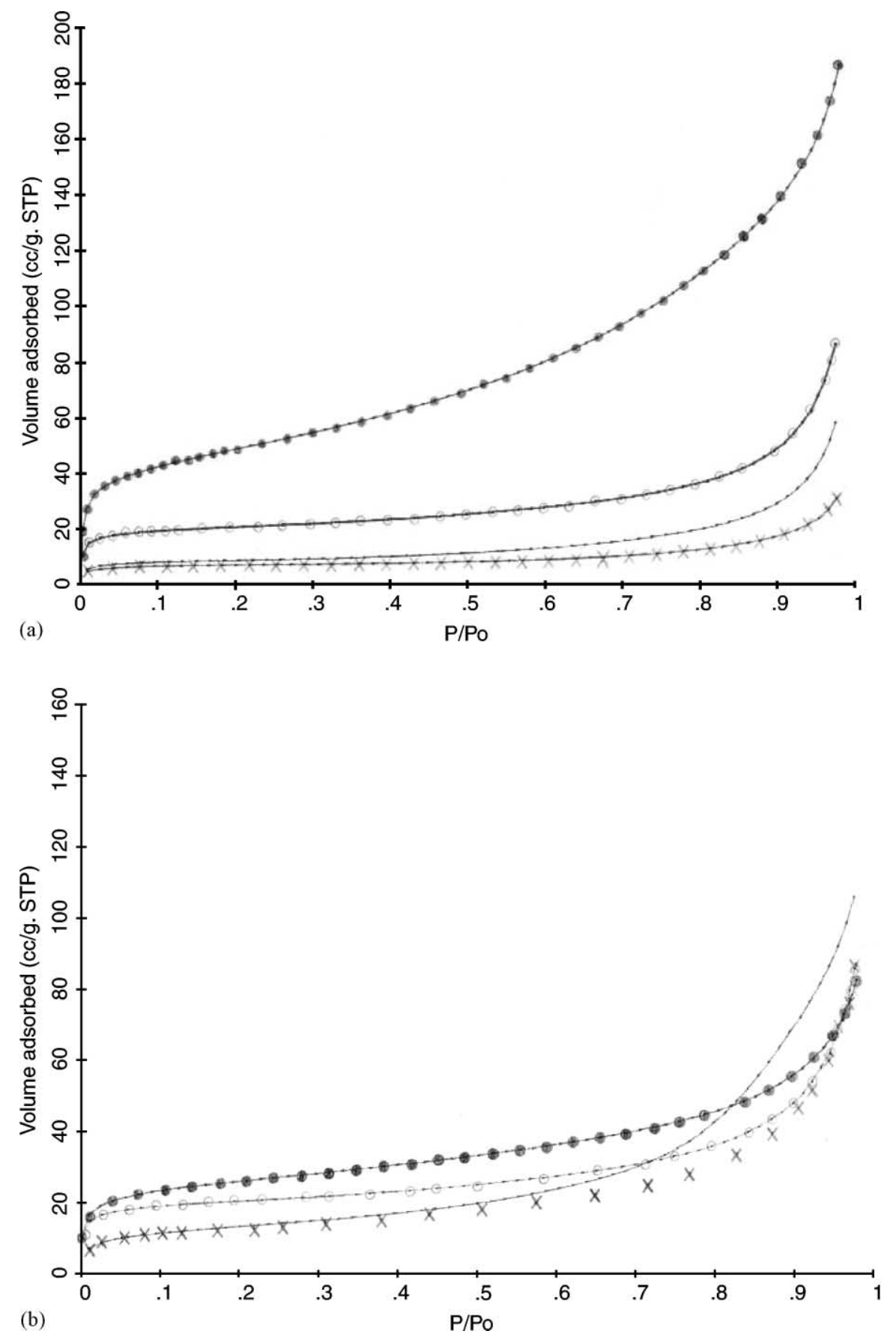

Fig. 2. (a) Nitrogen adsorption isotherms of clay catalysts prepared at $\mathrm{A} / \mathrm{C}=0.4, \mathrm{~W} / \mathrm{A}=4$ and activated at $150^{\circ} \mathrm{C}$. Original $(\mathrm{O}), t=3 \mathrm{~h}$ $(\times), t=4 \mathrm{~h}(\mathbf{O})$ and $t=5 \mathrm{~h}(-)$; and (b) Nitrogen adsorption isotherms of clay catalysts prepared at $\mathrm{W} / \mathrm{A}=4$ and activated at $200^{\circ} \mathrm{C}$. Original $(\bigcirc), \mathrm{A} / \mathrm{C}=0.2(\bigcirc), \mathrm{A} / \mathrm{C}=0.4(\times)$ and $\mathrm{A} / \mathrm{C}=0.8(-)$. 


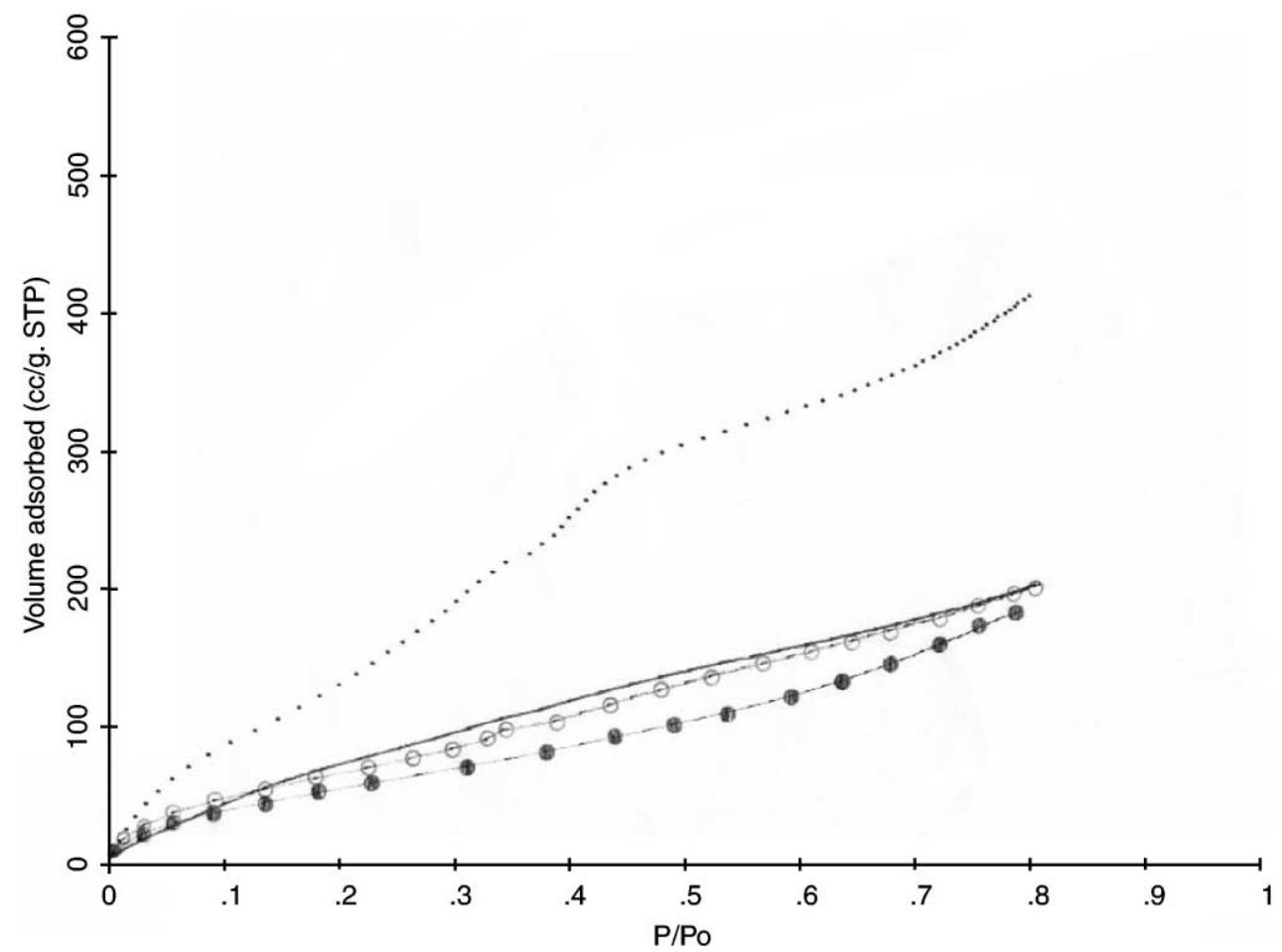

Fig. 3. Water vapor adsorption isotherms of clay catalysts prepared at $\mathrm{W} / \mathrm{A}=2$ and activated at $200{ }^{\circ} \mathrm{C}$ for $4 \mathrm{~h}$. Original $($ - $), \mathrm{A} / \mathrm{C}=0.2$ (O), $\mathrm{A} / \mathrm{C}=0.4(\mathbf{O})$ and $\mathrm{A} / \mathrm{C}=0.8(\cdots)$.

ature. Although a drastic change in micropore area is observed over sample K150-4 with increasing duration of pre-treatment, micropore area of sample K200-4 remains almost unchanged. This shows that the increase in temperature causes the removal of some microporosity of the original clay.

An increase in $\mathrm{A} / \mathrm{C}$ ratio causes the increase in the total and external surface areas, with a maximum at $\mathrm{A} / \mathrm{C}=0.4$. Micropore area generally decreases with acid treatment compared to raw clay, except sample K0.2-4. In case of samples with A/C $=0.8$, micropore surface areas almost disappear probably due to the drastic changes in structure.

The typical pore size distributions of clays for mesopore region by using nitrogen data are given in Figs. 4-6. On samples K150-3, K150-4 and K150-5 (which are related with acid at $\mathrm{A} / \mathrm{C}=0.4$ and $\mathrm{W} / \mathrm{A}=4)$, an increase in the ratio of differential volume of pores to differential radius of pore (DVP/DRP) at $2 \mathrm{~nm}$ is observed for sample $\mathrm{K} 150-4$ but a decrease for samples K150-3 and K150-5 (Fig. 4). For samples with $\mathrm{A} / \mathrm{C}=0.8$, an increase and a decrease in DVP/DRP ratios are observed for pores greater than $2 \mathrm{~nm}$ and pores around $2 \mathrm{~nm}$, respectively, with increasing W/A ratio (compare Figs. 5 and 6). In general, DVPs are affected by the acid treatment but pore sizes are not.

As stated before the radii of the pores corresponding to the maximum of curves for all samples have similar values $(\approx 2 \mathrm{~nm})$. However, individual curves differ in shape, showing different asymmetry which is connected with the geometric structure of mesopores. Asymmetry of differential curves indicates geometrical heterogeneity of mesopore sizes. The larger $\mathrm{A} / \mathrm{C}$ ratio used, the more mesopores are created. When the pore size distributions of acid-treated clays for water vapor data are investigated (Fig. 7), it is clearly seen that water adsorption covers a rather narrow range of sizes. This indicates that water is adsorbed in the interlaminar areas, resulting in high 
Table 1

Nitrogen and water vapor surface areas of various catalysts prepared

\begin{tabular}{|c|c|c|c|c|}
\hline Catalysts & $A_{\text {tot }}\left(\mathrm{m}^{2} / \mathrm{g}\right)$ & $A_{\text {ext }}{ }^{\mathrm{a}}\left(\mathrm{m}^{2} / \mathrm{g}\right)$ & $A_{\text {mic }}\left(\mathrm{m}^{2} / \mathrm{g}\right)$ & $A_{\mathrm{BET}}{ }^{\mathrm{b}}\left(\mathrm{H}_{2} \mathrm{O}\right)\left(\mathrm{m}^{2} / \mathrm{g}\right)$ \\
\hline \multicolumn{5}{|c|}{ Clay catalysts with $\mathrm{A} / \mathrm{C}=0.4, \mathrm{~W} / \mathrm{A}=4$} \\
\hline $\mathrm{K} 100-4$ & 31 & 19 & 12 & 151 \\
\hline K150-3 & 23 & 11 & 12 & 105 \\
\hline K150-4 & 143 & 132 & 12 & 232 \\
\hline K150-5 & 29 & 26 & 3 & 124 \\
\hline K200-3 & 43 & 40 & 3 & 207 \\
\hline K200-4 & 46 & 40 & 6 & 162 \\
\hline K200-5 & 36 & 31 & 5 & 149 \\
\hline \multicolumn{5}{|l|}{ Clay activated at $200^{\circ} \mathrm{C}, 4 \mathrm{~h}$} \\
\hline $\mathrm{K} 0.2-1(\mathrm{~A} / \mathrm{C}=0.2, \mathrm{~W} / \mathrm{A}=1.0)$ & 24 & 24 & $\mathrm{NC}^{\mathrm{c}}$ & 230 \\
\hline $\mathrm{K} 0.2-2(\mathrm{~A} / \mathrm{C}=0.2, \mathrm{~W} / \mathrm{A}=2.0)$ & 43 & 42 & 1 & 178 \\
\hline $\mathrm{K} 0.2-4(\mathrm{~A} / \mathrm{C}=0.2, \mathrm{~W} / \mathrm{A}=4.0)$ & 90 & 54 & 35 & 199 \\
\hline $\mathrm{K} 0.4-1(\mathrm{~A} / \mathrm{C}=0.4, \mathrm{~W} / \mathrm{A}=1.0)$ & 143 & 134 & 9 & 121 \\
\hline $\mathrm{K} 0.4-2(\mathrm{~A} / \mathrm{C}=0.4, \mathrm{~W} / \mathrm{A}=2.0)$ & 135 & 118 & 17 & 152 \\
\hline $\mathrm{K} 0.4-4(\mathrm{~A} / \mathrm{C}=0.4, \mathrm{~W} / \mathrm{A}=4.0)$ & 46 & & 6 & 162 \\
\hline $\mathrm{K} 0.8-1(\mathrm{~A} / \mathrm{C}=0.8, \mathrm{~W} / \mathrm{A}=1.0)$ & 57 & 57 & $\mathrm{NC}$ & 365 \\
\hline $\mathrm{K} 0.8-1(\mathrm{~A} / \mathrm{C}=0.8, \mathrm{~W} / \mathrm{A}=2.0)$ & 35 & 27 & 8 & 623 \\
\hline $\mathrm{K} 0.8-1(\mathrm{~A} / \mathrm{C}=0.8, \mathrm{~W} / \mathrm{A}=4.0)$ & 49 & 49 & $\mathrm{NC}$ & 502 \\
\hline Raw clay & 69 & 37 & 32 & 261 \\
\hline
\end{tabular}

${ }^{\mathrm{a}} A_{\text {ext }}: t$-plot surface areas.

${ }^{\mathrm{b}} A_{\mathrm{BET}}$ : BET surface areas.

${ }^{\mathrm{c}} \mathrm{NC}$ : not calculated.

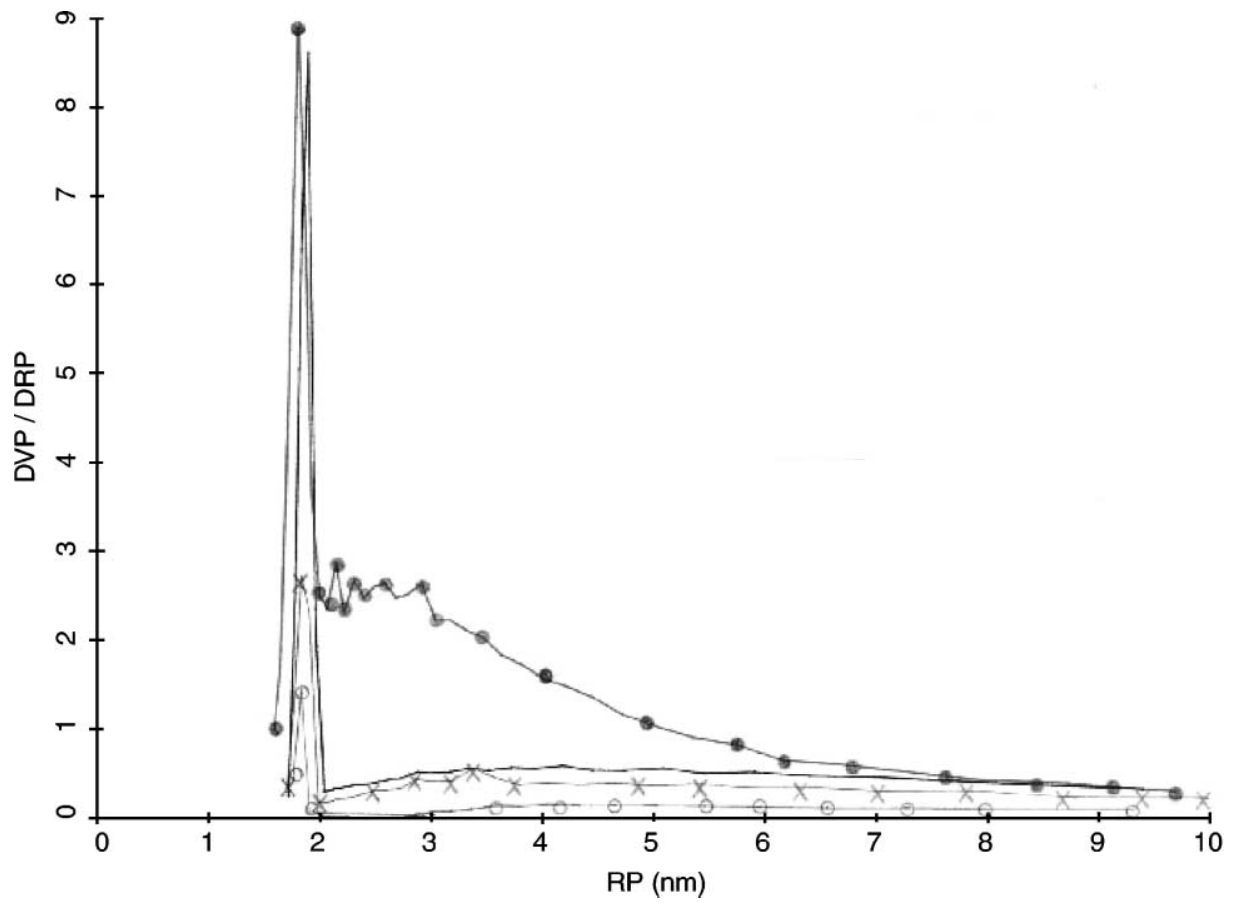

Fig. 4. Differential pore size distributions of clay catalysts prepared at $\mathrm{A} / \mathrm{C}=0.4, \mathrm{~W} / \mathrm{A}=4$ and activated at $150^{\circ} \mathrm{C}$ using nitrogen adsorption data. Original $(-), t=3 \mathrm{~h}(\bigcirc), t=4 \mathrm{~h}(\bigcirc)$ and $t=5 \mathrm{~h}(\times)$. 


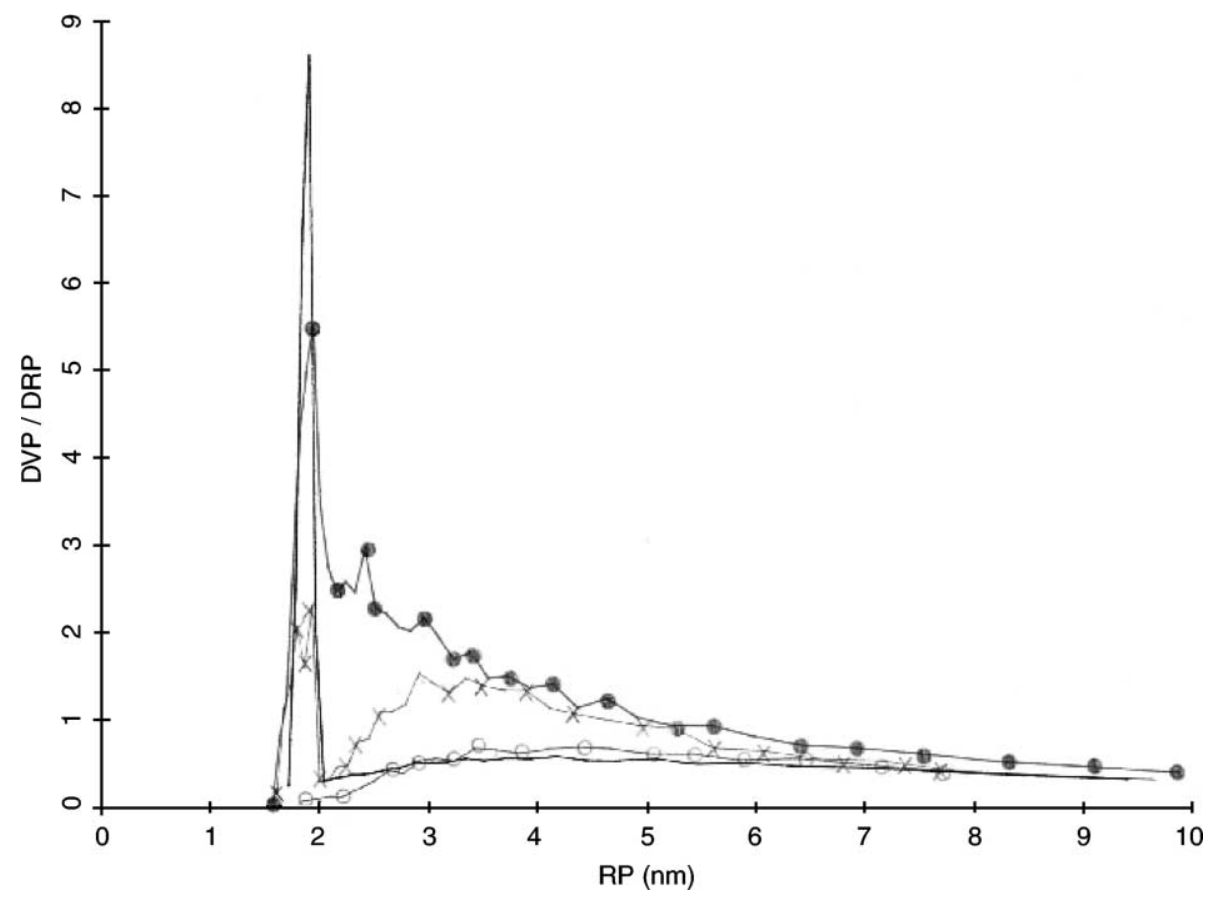

Fig. 5. Differential pore size distributions of clay catalysts prepared at $\mathrm{W} / \mathrm{A}=1$ and activated at $200{ }^{\circ} \mathrm{C}$ using nitrogen adsorption data. Original $(-), \mathrm{A} / \mathrm{C}=0.2(\mathrm{O}), \mathrm{A} / \mathrm{C}=0.4(\mathbf{O})$ and $\mathrm{A} / \mathrm{C}=0.8(\times)$.

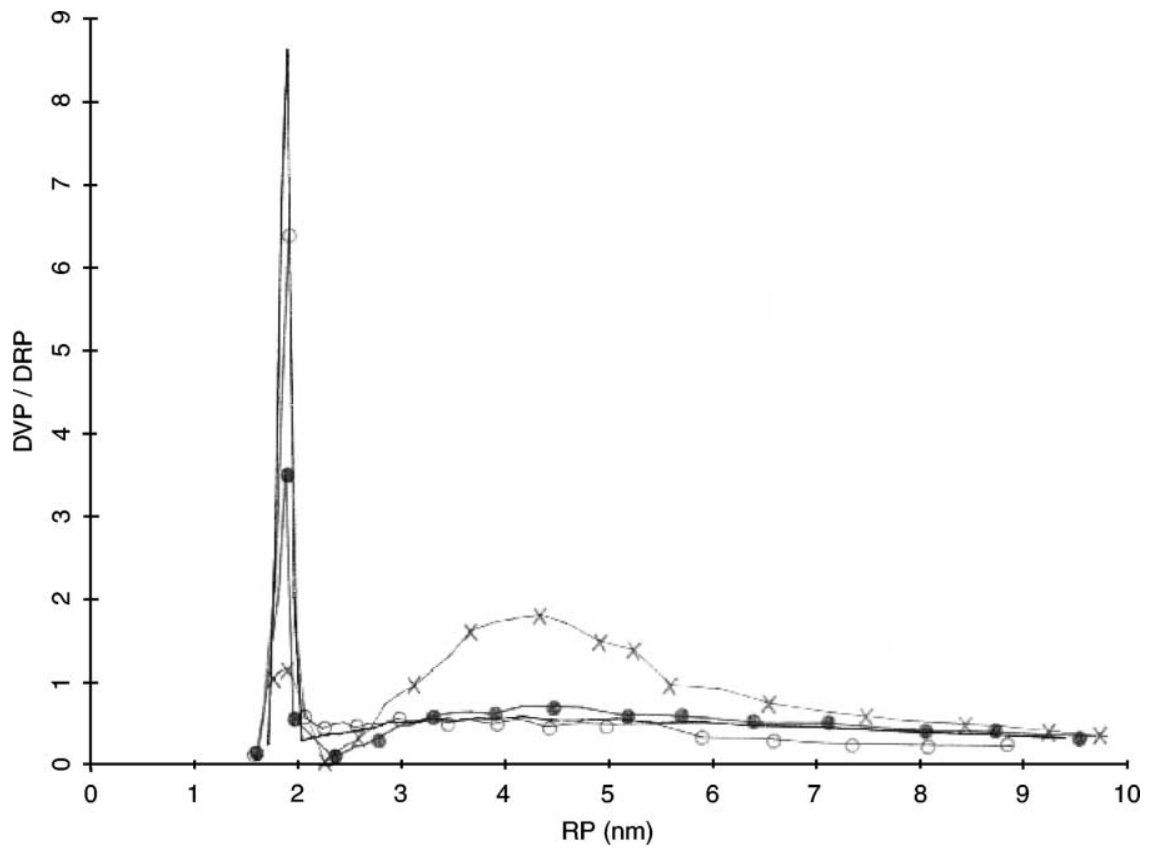

Fig. 6. Differential pore size distributions of clay catalysts prepared at $\mathrm{W} / \mathrm{A}=4$ and activated at $200{ }^{\circ} \mathrm{C}$ using nitrogen adsorption data. Original (一), $\mathrm{A} / \mathrm{C}=0.2(\mathrm{O}), \mathrm{A} / \mathrm{C}=0.4(\mathbf{O})$ and $\mathrm{A} / \mathrm{C}=0.8(\times)$. 


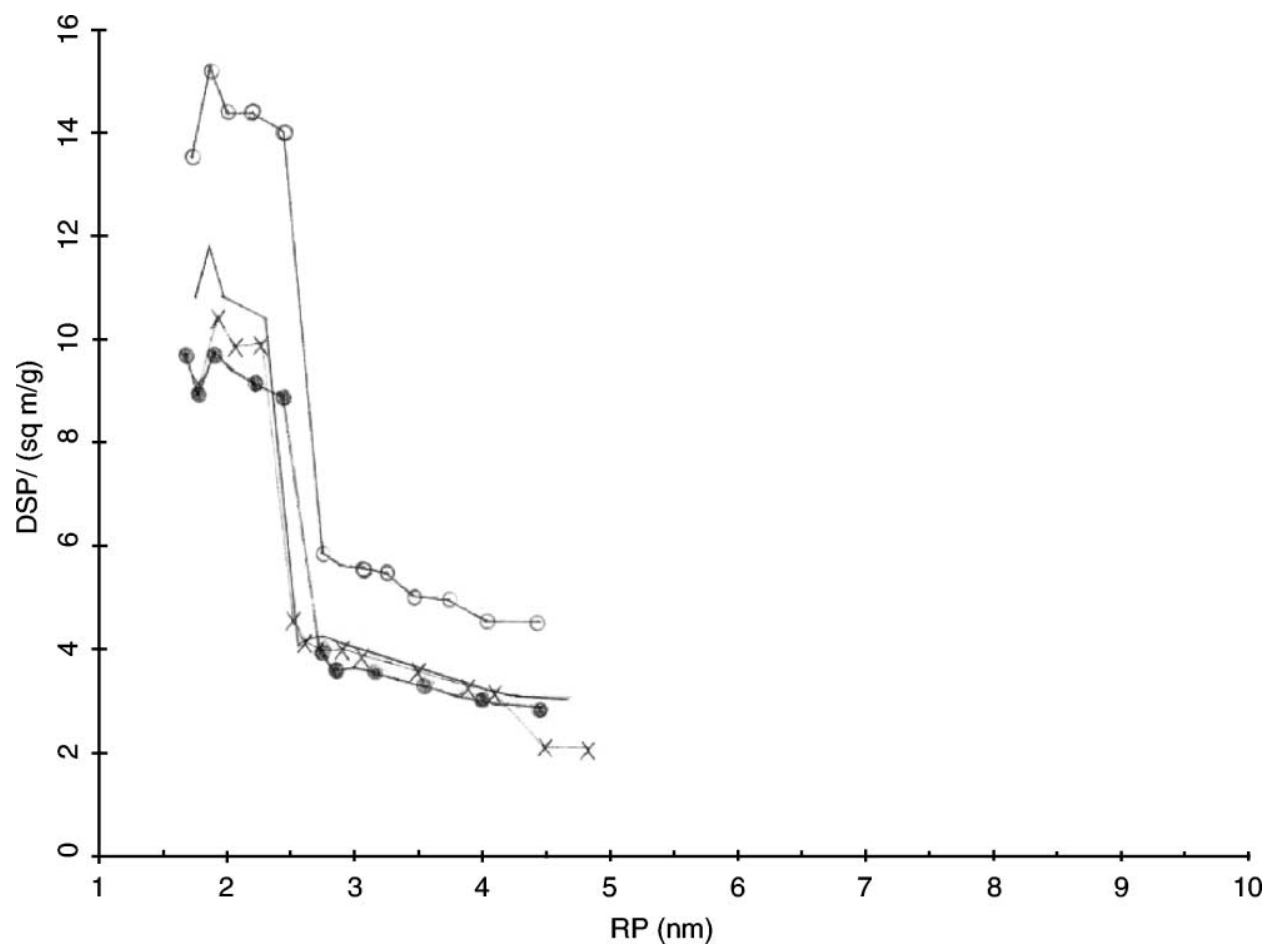

Fig. 7. Differential pore size distributions of clay catalysts prepared at $\mathrm{A} / \mathrm{C}=0.4$ and $\mathrm{W} / \mathrm{A}=4$ using water vapor adsorption data. Activation temperature: $200^{\circ} \mathrm{C}$. Original $(-), t=3 \mathrm{~h}(\mathrm{O}), t=4 \mathrm{~h}(\mathbf{O})$ and $t=5 \mathrm{~h}(\times)$.

Table 2

Conversion and selectivities to camphene, limonene and $p$-cymene in $\alpha$-pinene isomerization over various clay catalysts $(\%$, with an accuracy of \pm 1 )

\begin{tabular}{|c|c|c|c|c|}
\hline Catalyst & Code of catalyst & Total conversion & Selectivity to camphene & Selectivity to limonene \\
\hline Raw clay & - & 87 & 50 & - \\
\hline \multicolumn{5}{|c|}{ Clay activated at $\mathrm{A} / \mathrm{C}=0.4, \mathrm{~W} / \mathrm{A}=4$} \\
\hline $\mathrm{C}(200,3)$ & $\mathrm{K} 200-3$ & 50 & 42 & 27 \\
\hline $\mathrm{C}(200,4)$ & K200-4 & 99 & 45 & - \\
\hline $\mathrm{C}(200,5)$ & K200-5 & 36 & 37 & 31 \\
\hline $\mathrm{C}(150,3)$ & $\mathrm{K} 150-3$ & 1 & - & - \\
\hline $\mathrm{C}(150,4)$ & $\mathrm{K} 150-4$ & 99 & 35 & 10 \\
\hline $\mathrm{C}(150,5)$ & K150-5 & 99 & 40 & 2 \\
\hline $\mathrm{C}(100,4)$ & K100-4 & 99 & 39 & - \\
\hline \multicolumn{5}{|l|}{ Clay activated at $200^{\circ} \mathrm{C}, 4 \mathrm{~h}$} \\
\hline $\mathrm{C}(\mathrm{A} / \mathrm{C}=0.2, \mathrm{~W} / \mathrm{A}=4.0)$ & K0.2-4 & 99 & 40 & - \\
\hline $\mathrm{C}(\mathrm{A} / \mathrm{C}=0.2, \mathrm{~W} / \mathrm{A}=2.0)$ & $\mathrm{K} 0.2-2$ & 100 & 44 & - \\
\hline $\mathrm{C}(\mathrm{A} / \mathrm{C}=0.2, \mathrm{~W} / \mathrm{A}=1.0)$ & K0.2-1 & 99 & 35 & - \\
\hline $\mathrm{C}(\mathrm{A} / \mathrm{C}=0.4, \mathrm{~W} / \mathrm{A}=4.0)$ & K0.4-4 & 99 & 45 & - \\
\hline $\mathrm{C}(\mathrm{A} / \mathrm{C}=0.4, \mathrm{~W} / \mathrm{A}=2.0)$ & K0.4-2 & 99 & 40 & - \\
\hline $\mathrm{C}(\mathrm{A} / \mathrm{C}=0.4, \mathrm{~W} / \mathrm{A}=1.0)$ & K0.4-1 & 98 & 34 & - \\
\hline $\mathrm{C}(\mathrm{A} / \mathrm{C}=0.8, \mathrm{~W} / \mathrm{A}=4.0)$ & K0.8-4 & 52 & 43 & 27 \\
\hline $\mathrm{C}(\mathrm{A} / \mathrm{C}=0.8, \mathrm{~W} / \mathrm{A}=2.0)$ & K0.8-2 & 34 & 39 & 24 \\
\hline $\mathrm{C}(\mathrm{A} / \mathrm{C}=0.8, \mathrm{~W} / \mathrm{A}=1.0)$ & K0.8-1 & 21 & 73 & 49 \\
\hline
\end{tabular}


surface areas compared to those measured by nitrogen adsorption.

\subsection{Reaction studies}

On all acid-activated montmorillonites, the main products of $\alpha$-pinene isomerization are camphene, tricyclene, limonene, $\alpha$-fenchene, terpinolene, $p$ cymene, $\alpha$-phellanderene, $\alpha$ - and $\gamma$-terpinenes. Here, only the relationships between the acid activation characteristics (such as duration of activation, activation temperature, $\mathrm{A} / \mathrm{C}$ and W/A ratios, surface area, pore size distribution and structural changes) and the catalytic activity and selectivity towards camphene and limonene are presented.

A run took $3 \mathrm{~h}$. Samples of the solution were taken during the course of the reaction and analyzed by a GS + MS combination.

Total conversion and selectivities were calculated for the duration of reaction of $3 \mathrm{~h}$. Table 2 represents total conversion of $\alpha$-pinene and selectivities to camphene and limonene. As seen from Table 2, the A/C ratio has the largest effect on the reaction rate. At 0.2 and $0.4 \mathrm{~A} / \mathrm{C}$ ratios the influence of W/A ratio is negligible. At the same time at $\mathrm{A} / \mathrm{C}$ ratio of 0.8 , influence of W/A ratio is more pronounced. Pre-treatment with acid improves the catalytic activity at $\mathrm{A} / \mathrm{C}=0.2$ and $\mathrm{A} / \mathrm{C}=0.4$, but at 0.8 the conversion of $\alpha$-pinene decreases compared to the raw clay. In isomerization of $\alpha$-pinene, completeness of the reaction is desirable. When the reaction is not carried to completeness, unreacted $\alpha$-pinene remain in small percentages and because of the relative closeness of the boiling points of $\alpha$-pinene and camphene, separation by the ordinary methods of fractional distillation is not feasible [10].

From the same table, it is clearly seen that the catalyst pre-treated at $200{ }^{\circ} \mathrm{C}, \mathrm{A} / \mathrm{C}=0.2$ and $\mathrm{W} / \mathrm{A}=2.0$ can produce $100 \%$ conversion. At the same time this catalyst is one of the best for the camphene selectivity $(44 \%)$ too. For the production of limonene, the best choice $(31 \%)$ is to employ the catalyst coded K200-5 although total conversion of $\alpha$-pinene is rather low on it. The catalyst K150-3 is almost inactive for all the products.

When Figs. 4-6 and Table 2 are studied in detail, it is obvious that $\alpha$-pinene consumption is much less over the catalysts prepared at $\mathrm{A} / \mathrm{C}=0.8$ with differ- ent W/A ratios and over the catalysts K200-3, K200-5 and K150-3 than the others. The catalysts prepared at $\mathrm{A} / \mathrm{C}=0.8$ show an increase in differential pore volumes for pores greater than $2 \mathrm{~nm}$ and a decrease in differential pore volumes for pores around $2 \mathrm{~nm}$, with increasing W/A ratio. Catalysts K200-3, K200-5 and $\mathrm{K} 150-3$ are also the ones having low differential pore volumes for the pores around $2 \mathrm{~nm}$. In general, catalysts with high differential pore volumes for pores around $2 \mathrm{~nm}$ are good catalysts for the production of camphene.

\subsection{IR studies}

IR spectra of the acid-activated clays were recorded on $\mathrm{KBr}$ wafers. The IR absorbances at the wave number of $680-500 \mathrm{~cm}^{-1}$ due to the $\mathrm{AlO}_{6}$ octahedra in condensed state of the catalysts identify the dealumination peaks in the IR spectra. Descending orders of dealumination in the bar figures are obtained from IR spectra results by comparing the magnitude of the peak heights [26].

Figs. 8-10 show the product distributions over catalysts prepared under conditions of acid pre-treatment parameters (duration of pre-treatment, $\mathrm{A} / \mathrm{C}$ and W/A ratios). In these figures based on the reaction duration of $3 \mathrm{~h}$, the ordering of the catalysts has been done according to the dealumination decrease from clay structure. Table 3 presents the ratios of Lewis-to-Brönsted acid sites (L/B), calculated by using IR absorbance values at 1545 and $1450 \mathrm{~cm}^{-1}$ for the Brönsted and Lewis acid sites, respectively.

In Fig. 8, the effect of the pre-treatment time on product distribution is presented. As seen, type of the acid sites (Table 3) and dealumination degrees during the acid treatment at constant temperature of $200^{\circ} \mathrm{C}$ influence the distribution of the products. Weight percent of camphene in the reaction mixture increases as the dealumination of catalysts decreases and L/B ratio of catalysts increases. But as L/B ratio increases, production of limonene decreases. These results support the ones based on the studies of Severino et al. [16]. Values of Brönsted acid sites are nearly constant for all the catalysts in Fig. 8. However, it is clearly seen from Table 3, Lewis acid sites are significantly affected by the acid treatment process. It means that $\mathrm{L} / \mathrm{B}$ ratio is to be dominant on the distribution of reaction products in Fig. 8 . 


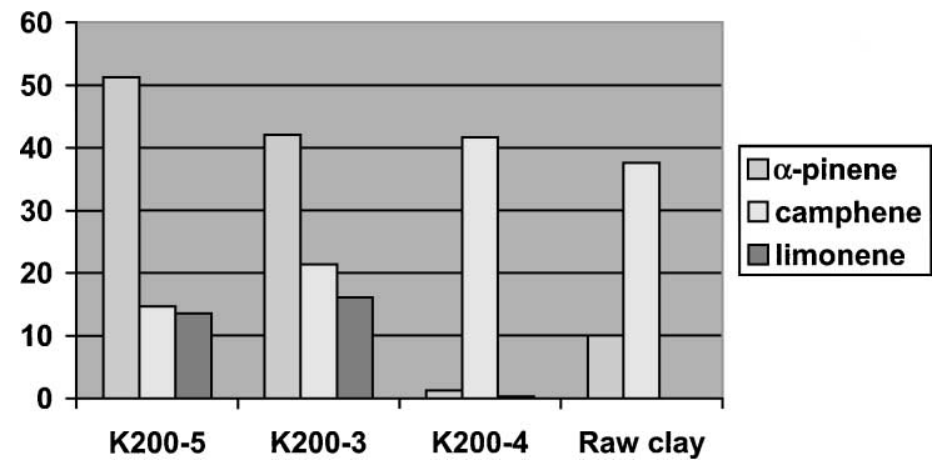

Fig. 8. Effect of activation time on the product distribution over several catalysts prepared (dealumination of the catalysts decreases from left to right).

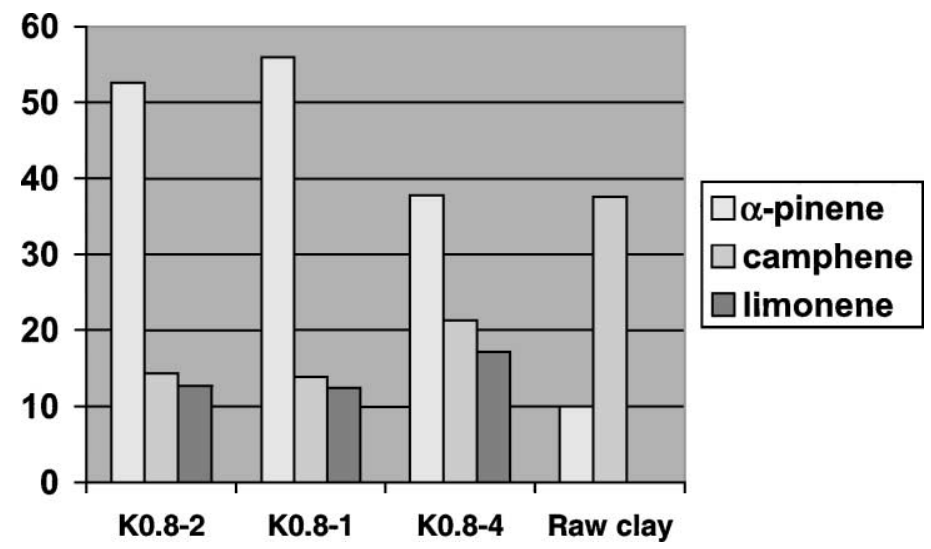

Fig. 9. Effect of W/A ratio on the product distribution over several catalysts prepared at $\mathrm{A} / \mathrm{C}=0.8$ (dealumination of the catalysts decreases from left to right).

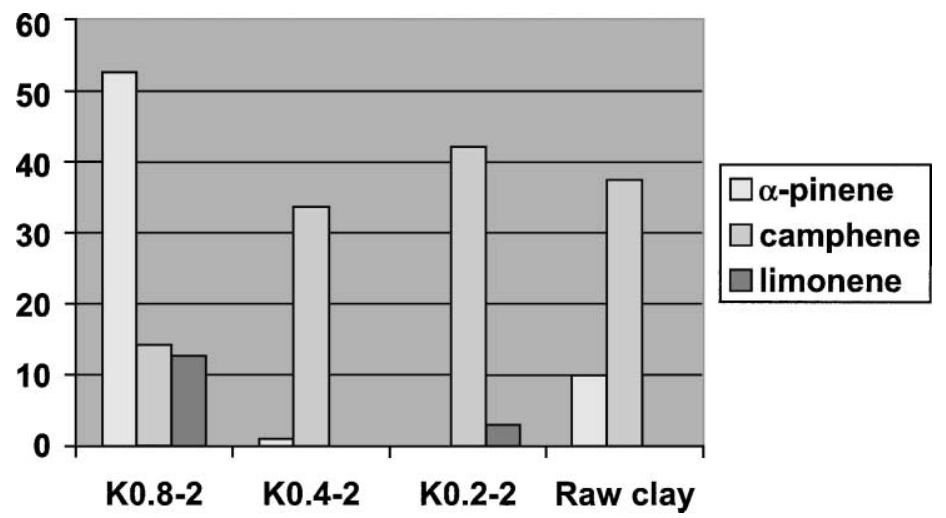

Fig. 10. Effect of $\mathrm{A} / \mathrm{C}$ ratio on the product distribution over several catalysts prepared at $\mathrm{W} / \mathrm{A}=2$ (dealumination of the catalysts decreases from left to right). 
Table 3

Absorbance values of acid sites on clay catalysts

\begin{tabular}{llll}
\hline Catalysts & $\begin{array}{l}\text { Lewis acid sites (L) } \\
\text { at } 1450 \mathrm{~cm}^{-1}\end{array}$ & $\begin{array}{l}\text { Brönsted acid sites (B) } \\
\text { at } 1545 \mathrm{~cm}^{-1}\end{array}$ & $\begin{array}{l}\text { Lewis-to-Brönsted acid } \\
\text { sites ratio (L/B) }\end{array}$ \\
\hline Raw clay & 0.144 & 0.192 & 0.522 \\
K200-3 & 0.038 & 0.053 & 0.725 \\
K200-4 & 0.052 & 0.050 & 1.040 \\
K200-5 & 0.020 & 0.048 & 0.416 \\
K0.8-1 & 0.052 & 0.030 & 1.750 \\
K0.8-2 & 0.060 & 0.051 & 1.176 \\
K0.8-4 & 0.037 & 0.059 & 0.630 \\
K0.2-2 & - & 0.137 & - \\
K0.4-2 & - & 0.090 & - \\
\hline
\end{tabular}

Amount of camphene is the highest over the K200-4 catalyst and this catalyst has high differential pore volumes around $2 \mathrm{~nm}$ and homogeneous mesoporosity (Fig. 6).

In Fig. 9, the effects of W/A ratios (at constant $\mathrm{A} / \mathrm{C}=0.8$ ) on product distributions are shown. Amount of camphene is low over the catalysts with high dealumination degrees because of the low values of the Brönsted acid sites. As W/A ratios increase Brönsted acid sites increase, so both amounts of camphene and limonene in the reaction mixture increase. The increase in camphene amount with Brönsted acid sites is in a good accordance with the studies of Grzona et al. [20]. As stated by Severino et al., limonene is preferentially formed over Brönsted acid sites. That is why, the increase in limonene amount with Brönsted acid sites is expected if the rate of the secondary reactions of limonene are low. All these catalysts have heterogeneous mesopore distributions and low differential volume of pores around pore sizes of $2 \mathrm{~nm}[5,6]$.

Fig. 10 shows the effects of the $\mathrm{A} / \mathrm{C}$ ratios on the product distributions at constant $\mathrm{W} / \mathrm{A}=2$. As the $\mathrm{A} / \mathrm{C}$ ratios decrease the values of Brönsted acid sites increase and amount of camphene is to be its highest value. Contrary to this result, Lewis acid sites disappear (Table 3) by decreasing A/C ratios. Amount of limonene decreases while Brönsted acid sites increase because of increasing rates of secondary reactions of limonene. Catalysts in Fig. 9 have low values of Brönsted acid sites more than those of in Fig. 10. But, over the catalysts which have this low value of Brönsted acid sites, as Brönsted acid sites increase, weight percent of limonene in the reaction increases because values of Brönsted sites are not high enough to increase the rates of the secondary reactions of limonene.

Catalyst K0.2-2 with the stronger Brönsted acid sites than the others in Fig. 10, shows the highest amount of camphene and this catalyst has the homogeneous mesopore distribution with highest micropore volume around $2 \mathrm{~nm}$. But in general without acid treatment, raw clay is an effective catalyst in the production of camphene for the reaction time of $3 \mathrm{~h}$, however, isomerization reaction is not carried to completeness over raw clay, which is not desired.

\section{Conclusion}

The results in this study, show that it is possible to establish good relationship between the acidity, pore size distributions of catalysts and the product distribution in $\alpha$-pinene isomerization. It can be exactly said that the catalysts such as K200-4 and K0.2-2 were active for producing camphene when they presented Brönsted acidity [20]. However, camphene is preferentially formed over Lewis acid sites for high enough values of L/B ratios. Increase of the Brönsted acid sites promotes the formation of limonene providing high rates of secondary reactions of limonene, only for high enough values of Brönsted sites. This result is in conformity with the one reported by Severino et al. [16]. High A/C ratio such as 0.8 , causes drastic changes in structure and considerable drops in activity of the catalysts are observed. The $\mathrm{A} / \mathrm{C}$ and $\mathrm{W} / \mathrm{C}$ ratios directly affect the dealumination degrees of catalysts corresponding to changes in the extent of acidity of the catalysts. The differences created in the distribution of Brönsted and Lewis acid sites in catalysts by acid 
treatment cause significant changes on product distributions in $\alpha$-pinene isomerization. As a result, it can be concluded that the catalysts with acid sites which Brönsted sites are dominant, with high pore volumes for the pores around $2 \mathrm{~nm}$ and homogeneous mesopore distributions with low dealumination degrees are good catalysts for the production of camphene.

\section{Acknowledgements}

We thank Serpil Taskiran and Ilhami Taskiran for their valuable helps in adsorption measurements and GC analysis, respectively.

\section{References}

[1] S.V. Korotov, V.A. Vyrodov, E.V. Afanas'eva, A.I. Kolesov, Z.L., Maslakova, T.D. Oblivantseva, P.K. Cheirkov, P.I. Zhurovlev, O.I. Minaeva, USSR Patent No. 238,541 (1969).

[2] E.V. Afanas'eva, V.A. Vyrodov, S.V. Korotov, Nauch. Tr. 135 (1) (1970) 11.

[3] E.V. Afanas'eva, V.A. Vyrodov, S.V. Korotov, Nauch. Tr. 135 (1) (1970) 20.

[4] Y. Matsubara, Y. Butani, S. Wakabayashi, Y. Watanabe, A. Takamatsu, M. Morita, Japanese Patent No. 28,575 (1970).

[5] A.A. Popov, V.A. Vyrodov, Lesokhim. Prom.-St. 6 (1979) 18.

[6] S.B. Battolova, T.R. Mukitanova, K.G. Tabenova, Vest. Akad. Nauk. Kaz. SSR 52 (1990) 10.
[7] S. Kullaj, Bull. Shkoncave Nat. 39 (4) (1985) 47.

[8] S. Kullaj, Bull. Shkoncave Nat. 43 (1) (1989) 81.

[9] M. Nazir, M. Ahmed, F.M. Chaudhary, Pak. J. Sci. Ind. Res. 19 (3/4) (1976) 175.

[10] W.F. Carson, US Patent No. 2,382,397 (1945).

[11] W.J. Kirkpatrick, US Patent No. 2,385,711 (1945).

[12] S. Findik, G. Gunduz, Journal of the American Oil Chemists Society 74 (9) (1997) 1145

[13] A. Allahverdiev, G. Gündüz, D.Y. Murzin, Ind. Eng. Chem. Res. 37 (1998) 2377.

[14] A. Allahverdiev, N.A. Sokolava, G. Gündüz, N.V. Kul'kova, Russ. J. Phys. Chem. 72 (10) (1998) 1647.

[15] C.B. Davis, J.J. McBride, US Patent No. 3,824,135 (1974).

[16] A. Severino, A. Esculcas, J. Rocha, J. Vital, L.S. Lobo, Appl. Catal.: Gen. 142 (1996) 255.

[17] A. Allahverdiev, S. Irandoust, D.Yu. Murzin, J. Catal. 185 (1999) 352-362.

[18] T. Yamamato, T. Matsuyama, T. Tanaka, T. Funabiki, S. Yoshida, Phys. Chem. Chem. Phys. 1 (1999) 2841-2849.

[19] T. Yamamato, T. Matsuyama, T. Tanaka, T. Funabiki, S. Yoshida, J. Mol. Catal. A: Chem. 155 (2000) 43-58.

[20] L. Grzano, N. Comelli, O. Masini, E. Ponzi, M. Ponzi, React. Kinet. Catal. Lett. 69 (2) (2000) 271-276.

[21] R. Mokaya, W. Jones, J. Catal. 153 (1995) 76.

[22] N. Besun, Ph.D. Thesis, Ege University, Izmir, Turkey, 1990.

[23] R.D. Heyding, R. Ironside, A.R. Noris, R.Y. Prysiazniuk, Can. J. Chem. 38 (1960) 1003.

[24] A. Wali, S. Unnikrishnan, S.M. Pillai, V.K. Kaushik, S. Satish, J. Catal. 173 (1998) 84-94.

[25] S.J. Gregg, K.S. Sing, Adsorption, Surface Area and Porosity, Academic Press, London, 1982, p. 216.

[26] A.D. Stefanis, G. Perez, O. Ursini, A.A.G. Tomlinson, Appl. Catal. A: Gen. 132 (1995) 353. 